\title{
OPEN Integrated biocontrol of tobacco bacterial wilt by antagonistic bacteria and marigold
}

\author{
Yun $\mathrm{Hu}^{1,4}$, Wan $\mathrm{Zhao}^{1,4}$, Xihong $\mathrm{Li}^{2}$, Ji Feng ${ }^{2}$, Chunli Li ${ }^{1}$, Xiaoqiong Yang ${ }^{1}$, Qingqing Guo ${ }^{1}$, \\ Lin Wang ${ }^{3}$, Shouwen Chen ${ }^{1}$, Yanyan $\mathrm{Li}^{2 \bowtie}$ \& Yong Yang ${ }^{1 \bowtie}$
}

Tobacco bacterial wilt (TBW) is seriously damages the growth of tobacco. There is an urgent need to find a safer and more effective measure to control TBW. In this study, B. amyloliquefaciens ZM9 and marigold powder were applied to the tobacco roots alone or in combination, and the potential inhibition of TBW was assessed. On the other hand, the effects of these treatments on soil physicochemical properties, rhizosphere microbial community and soil metabolites were also evaluated. The results showed that the application of $B$. amyloliquefaciens ZM9 or marigold powder alone significantly reduced the abundance of $R$. solanacearum in rhizosphere soil, while the integrated treatment showed the strongest inhibitory effect. Moreover, the integrated treatment can inhibit the secretion of chemoattractants, and affect the change of rhizosphere soil microbial composition. In conclusion, the combination of antagonistic bacteria agent $B$. amyloliquefaciens ZM9 with marigold powder can enhance the suppression of TBW. Furthermore, B. amyloliquefaciens ZM9 and marigold have synergistic effects on suppressing TBW by regulation soil physicochemical properties, soil metabolites and microbial structure. This study provide a promising strategy for TBW control by integrated applying of $B$. amyloliquefaciens ZM9 and marigold powder.

Bacterial wilt is a typical soil-borne disease caused by $R$. solanacearum, which seriously damages the growth of tobacco ${ }^{1}$. It is distributed in almost all the flue-cured tobacco growing areas in the world, especially in tropical and subtropical tobacco areas, which is a major devastating disease threatening world tobacco production and causing great economy loss ${ }^{2}$. Therefore, the control of bacterial wilt has been a worldwide problem. Lots of researches on the control of bacterial wilt in breeding resistant varieties, chemical control, agricultural control. However, these traditional control methods have limited efficacy and many problems, such as lack of resistant varieties, poor control efficacy, pathogen resistant, environmental pollution, and so on ${ }^{3,4}$. There is an urgent need to find effective and environmentally friendly measures to control bacterial wilt.

Biocontrol is widely used for prevention and control of bacterial wilt ${ }^{5}$. Antagonistic bacteria, as the most common method of biocontrol can reduce the harm of pathogens to plants, and promote plant growth ${ }^{6,7}$. The main biocontrol bacterial include Bacillus spp., Pseudomonas spp., Streptomyces spp. and so on ${ }^{8-10}$. Among them, the bioactive peptides produced by Bacillus spp. have potential inhibitory effect on plant pathogens, and bacillus can form spore state under condition stress, which is easy to be stored and transported as stable products ${ }^{11,12}$. Our previous study showed that B. amyloliquefaciens ZM9 as an efficient biocontrol agent can suppress tobacco bacterial wilt (TBW) $)^{13,14}$. However, the control effect of single antagonistic bacteria in different regions and different crops is very different, and it is easy to be affected by external climate factors and farming conditions, resulting in unstable control ${ }^{15}$.

Marigold (Tagetes erecta L.) is a common garden flower, which can be used for ornamental, medical and pharmaceutical purposes ${ }^{16}$. It is reported that marigold contains allelopathy compounds (such as $\alpha$-terthiophene) and has antibacterial activity, which can effectively protect plants against parasitic nematodes ${ }^{17,18}$. Marigold also has been reported to successfully suppress $R$. solanacearum when used as a rotational or intercropping plant under greenhouse conditions ${ }^{19}$. In our previous study, we found that marigold and tobacco intercropping can effectively reduce the incidence of TBW, affect the soil microbial community and soil physicochemical properties ${ }^{20}$. Kamal et al. found that the combination of biocontrol agents and resistance inducers could make biocontrol

\footnotetext{
${ }^{1}$ State Key Laboratory of Biocatalysis and Enzyme Engineering, School of Life Science, Hubei University, Wuhan 430062, China. ${ }^{2}$ Tobacco Research Institute of Hubei Province, Wuhan 430030, China. ${ }^{3}$ Hubei Tobacco Industry Co., Ltd., Wuhan 430040, China. ${ }^{4}$ These authors contributed equally: Yun Hu and Wan Zhao. ${ }^{\square}$ email: yanyanli0025@126.com; yangyong@hubu.edu.cn
} 


\begin{tabular}{|l|l|l|l|l|l|l|}
\hline \multirow{2}{*}{ Treatments } & \multicolumn{3}{|l|}{$\mathbf{5 0}$ days post-transplantation } & \multicolumn{2}{l|}{$\mathbf{7 0}$ days post-transplantation } & \multicolumn{2}{l|}{ 90 days post-transplantation } \\
\cline { 2 - 7 } & $\begin{array}{l}\text { Disease incidence } \\
(\%)\end{array}$ & Disease index & $\begin{array}{l}\text { Disease incidence } \\
(\%)\end{array}$ & Disease index & $\begin{array}{l}\text { Disease incidence } \\
(\%)\end{array}$ & Disease index \\
\hline CK & $26.37 \pm 0.59 \mathrm{a}$ & $19.23 \pm 1.12 \mathrm{a}$ & $56.56 \pm 2.98 \mathrm{a}$ & $37.37 \pm 1.18 \mathrm{a}$ & $92.00 \pm 3.56 \mathrm{a}$ & $47.52 \pm 1.25 \mathrm{a}$ \\
\hline T1 & $5.06 \pm 2.18 \mathrm{c}$ & $3.42 \pm 0.48 \mathrm{c}$ & $6.95 \pm 1.24 \mathrm{c}$ & $5.02 \pm 0.25 \mathrm{c}$ & $17.33 \pm 2.54 \mathrm{c}$ & $8.28 \pm 0.60 \mathrm{c}$ \\
\hline T2 & $7.28 \pm 1.05 \mathrm{bc}$ & $6.85 \pm 0.23 \mathrm{~b}$ & $20.36 \pm 2.51 \mathrm{~b}$ & $12.97 \pm 1.93 \mathrm{~b}$ & $24.33 \pm 1.85 \mathrm{~b}$ & $15.89 \pm 0.18 \mathrm{~b}$ \\
\hline T3 & $8.98 \pm 1.11 \mathrm{~b}$ & $7.67 \pm 1.17 \mathrm{~b}$ & $21.13 \pm 1.59 \mathrm{~b}$ & $13.47 \pm 1.92 \mathrm{~b}$ & $25.07 \pm 2.31 \mathrm{~b}$ & $16.45 \pm 1.90 \mathrm{~b}$ \\
\hline
\end{tabular}

Table 1. The occurrence of tobacco bacterial wilt of four treatments. All data are presented as the mean \pm SE. CK: the control group, T1: marigold powder mix with B. amyloliquefaciens ZM9 group, T2: B. amyloliquefaciens ZM9 group, T3: marigold powder. The different letters in the same column indicate significant differences at $p<0.05$ according to LSD test.

\begin{tabular}{|l|l|l|l|l|}
\hline & HN $(\mathbf{m g} / \mathbf{k g})$ & $\mathbf{A P}(\mathbf{m g} / \mathbf{k g})$ & $\mathbf{A K}(\mathbf{m g} / \mathbf{k g})$ & $\mathbf{p H}$ \\
\hline CK_0d & $108.52 \pm 12.16 \mathrm{a}$ & $35.33 \pm 0.44 \mathrm{a}$ & $267.97 \pm 9.77 \mathrm{a}$ & $6.24 \pm 0.05 \mathrm{a}$ \\
\hline T1_0d & $110.49 \pm 9.73 \mathrm{a}$ & $35.51 \pm 0.86 \mathrm{a}$ & $267.96 \pm 8.62 \mathrm{a}$ & $6.25 \pm 0.03 \mathrm{a}$ \\
\hline T2_0d & $109.17 \pm 5.24 \mathrm{a}$ & $35.43 \pm 1.13 \mathrm{a}$ & $272.05 \pm 6.55 \mathrm{a}$ & $6.23 \pm 0.05 \mathrm{a}$ \\
\hline T3_0d & $108.91 \pm 6.56 \mathrm{a}$ & $35.91 \pm 1.24 \mathrm{a}$ & $271.50 \pm 9.76 \mathrm{a}$ & $6.25 \pm 0.03 \mathrm{a}$ \\
\hline CK_50d & $154.07 \pm 10.76 \mathrm{a}$ & $40.46 \pm 2.02 \mathrm{c}$ & $386.91 \pm 3.77 \mathrm{~d}$ & $5.35 \pm 0.02 \mathrm{c}$ \\
\hline T1_50d & $121.75 \pm 1.38 \mathrm{~b}$ & $64.08 \pm 3.65 \mathrm{a}$ & $1085.53 \pm 2.53 \mathrm{a}$ & $5.98 \pm 0.03 \mathrm{a}$ \\
\hline T2_50d & $123.32 \pm 2.46 \mathrm{~b}$ & $49.12 \pm 1.79 \mathrm{~b}$ & $915.72 \pm 5.42 \mathrm{~b}$ & $5.53 \pm 0.09 \mathrm{c}$ \\
\hline T3_50d & $133.43 \pm 2.27 \mathrm{~b}$ & $49.59 \pm 2.13 \mathrm{~b}$ & $754.54 \pm 12.31 \mathrm{c}$ & $5.74 \pm 0.12 \mathrm{~b}$ \\
\hline CK_70d & $175.69 \pm 3.09 \mathrm{a}$ & $51.14 \pm 2.74 \mathrm{c}$ & $849.22 \pm 12.44 \mathrm{~d}$ & $4.53 \pm 0.01 \mathrm{c}$ \\
\hline T1_70d & $145.92 \pm 4.39 \mathrm{c}$ & $80.63 \pm 1.65 \mathrm{a}$ & $1596.84 \pm 1.84 \mathrm{a}$ & $5.28 \pm 0.06 \mathrm{a}$ \\
\hline T2_70d & $160.17 \pm 0.85 \mathrm{~b}$ & $71.47 \pm 3.99 \mathrm{~b}$ & $1344.11 \pm 6.41 \mathrm{~b}$ & $5.12 \pm 0.03 \mathrm{~b}$ \\
\hline T3_70d & $163.26 \pm 2.43 \mathrm{~b}$ & $72.17 \pm 3.82 \mathrm{~b}$ & $1057.53 \pm 16.38 \mathrm{c}$ & $5.11 \pm 0.04 \mathrm{~b}$ \\
\hline CK_90d & $167.43 \pm 4.14 \mathrm{a}$ & $44.72 \pm 1.87 \mathrm{c}$ & $682.46 \pm 11.21 \mathrm{~d}$ & $5.03 \pm 0.03 \mathrm{c}$ \\
\hline T1_90d & $131.53 \pm 2.22 \mathrm{~b}$ & $76.23 \pm 3.31 \mathrm{a}$ & $1335.63 \pm 4.08 \mathrm{a}$ & $5.64 \pm 0.03 \mathrm{a}$ \\
\hline T2_90d & $135.00 \pm 3.00 \mathrm{~b}$ & $63.70 \pm 1.41 \mathrm{~b}$ & $929.20 \pm 1.10 \mathrm{~b}$ & $5.18 \pm 0.06 \mathrm{~b}$ \\
\hline T3_90d & $133.93 \pm 2.40 \mathrm{~b}$ & $63.75 \pm 2.71 \mathrm{~b}$ & $890.65 \pm 12.62 \mathrm{c}$ & $5.20 \pm 0.03 \mathrm{~b}$ \\
\hline
\end{tabular}

Table 2. Soil chemical properties in four treatments at 0 days, 50 days, 70 days and 90 days post-transplanted, respectively. Soil chemical properties in soils are presented as the mean \pm SE. CK: the control group, T1: $B$. amyloliquefaciens ZM9 mix with marigold powder group, T2: B. amyloliquefaciens ZM9 group, T3: marigold powder. The different letters in the same column indicate significant differences as determined by LSD test. $p<0.05$.

agents better adapt to environment changes and effectively control of bacterial wilt ${ }^{21}$. Thus, integrated control approaches should be taken into consideration for controlling bacterial wilt more effectively.

In this study, a field trail was carried out in a TBW prone area in Enshi City of Hubei province, China. Antagonistic bacteria B. amyloliquefaciens ZM9 and antibacterial plant marigold were applied to tobacco field. The main objectives of this study were to (1) evaluate the potential of antagonistic bacteria B. amyloliquefaciens ZM9 and antibacterial plant marigold, alone or in combination, to suppress TBW; and (2) investigate the effects of these treatments on soil physicochemical properties, rhizosphere microbial community and soil metabolites. We hypothesized that application of B. amyloliquefaciens ZM9 and marigold could alter soil physicochemical properties, microbial abundance and soil metabolites, thus inhibiting TBW. This study proposed a new approach to control TBW by combining of B. amyloliquefaciens ZM9 and marigold.

\section{Results}

The incidence and index of TBW. Symptoms of TBW were recorded at 50 days, 70 days and 90 days post-transplantation, and the disease incidence (I) and disease index (DI) of TBW were calculated. From 50 to 90 days post-transplantation, the I and DI gradually increased. In addition, the I and DI of the CK group were significantly higher than other treatment groups. While, the I and DI of T1 group were significantly lower than other treatment groups (Table 1). The results indicated that $\mathrm{T} 1, \mathrm{~T} 2$ and $\mathrm{T} 3$ groups can effectively restrained the incidence and severity of TBW, and the T1 treatment group had the best inhibitory effect among all treatment groups.

Rhizosphere soil physicochemical properties. Four physicochemical properties of the rhizosphere soil at 0 days, 50 days, 70 days and 90 days post-transplantation were analyzed (Table 2). At 0 day, there was no significant difference in $\mathrm{pH}$, hydrolysable nitrogen (HN), available phosphorous (AP) and available potas- 
sium (AK) among different treatment groups. From 50 to 90 days post-transplantation, there was significant difference in $\mathrm{pH}, \mathrm{HN}, \mathrm{AP}$ and $\mathrm{AK}$ between the $\mathrm{CK}$ group and other treatment groups. The HN content in the CK group was observed higher than that in other treatment groups, and gradually increased from 50 to 90 days post-transplantation. While, among all treatment groups, the T1 treatment group contained the lowest HN. Additionally, the values of $\mathrm{pH}, \mathrm{AP}$ and $\mathrm{AK}$ were lowest in the $\mathrm{CK}$ group and highest in $\mathrm{T} 1$ treatment group. The $\mathrm{AP}$ and $\mathrm{AK}$ content in the T1 treatment group increased from 50 to 70 days post-transplantation, and decreased at $90 \mathrm{~d}$ post-transplantation (Table 2). What's more, $\mathrm{pH}$ (Pearson $=-0.843, p=0.031)$, AP (Pearson $=-0.286$, $p=0.002)$ and AK (Pearson $=-0.725, p=0.005)$ showed significantly negative correlation with the incidence of TBW (Table S1).

Bacterial diversity and community structure in soil. In total, 163,609 high-quality raw sequences with an average length of 251 bps for bacteria were obtained from rhizosphere soil samples after removing lowquality reads. The OTUs, Chaol and Shannon index were used to evaluate and compare the diversity and richness of bacterial community among different treatment groups (Table S2). From 50 to 90 days post-transplantation, the OTUs and Shannon index were both significantly lower in the CK group than in the other treatment groups. Analysis by Chao1, a lower richness of bacteria was also found in the CK group. Moreover, the OTUs, Chaol and Shannon index were higher in the T1 treatment group than in the other treatment groups. These results indicated that $\mathrm{T} 1$ treatment group had a higher bacteria diversity and richness than the other treatment groups. This suggested that $\mathrm{T} 1$ treatment group could effectively improve bacterial community diversity.

Bacterial were identified as 48 phyla from all soil samples. The top six abundant bacterial phyla were selected to compare the changes of bacterial communities in rhizosphere soil of different treatments (Fig. 1a). From 50 to 90 days post-transplantation, Proteobacteria was dominant (50.0-70.0\%), followed by Actinobacteria (5.6-12.0\%), Acidobacteria (7.1-9.0\%), Gemmatimonadetes (7.1-9.0\%), Bacteroidetes (5.9-6.7\%) and Planctomycetes $(0.20-0.2 \%)$. The relative abundance of the phylum Proteobacteria included the pathogen $R$. solanacearum was higher in the CK than other treatment groups. On the other hand, Actinobacteria, Acidobacteria and Gemmatimonadetes were abundant in T1 treatment compared to the other treatments. In addition, the relative abundance of Proteobacteria was increased from 50 to 90 days post-transplantation. While the relative abundance of other phyla were slight decreased from 50 to 90 days post-transplantation, indicating the relative abundance of bacterial phyla changed during different tobacco growth stages. PCA analyses based on the weighted Unifrac distance showed differences in soil bacterial community structure among different treatments. PC1 and PC2 explained $32.42 \%$ and $17.21 \%$ of the total bacterial community variations respectively. T1 (T1_50, T1_70, T1_90), T2 (T2_50, T2_70, T2_90), T3 (T3_50, T3_70, T3_90) and CK (CK_50, CK_70, CK_90) treatments were respectively clustered together and separated from each other (Fig. 1b). The results of the PCA suggested different treatments played important impact on the structure of soil bacterial community. The Heatmap analysis of the top 35 genera with hierarchical clusters was used to identify the different composition of bacterial community structure (Fig. 1c). Different treatments in different period were divided into four broad categories, suggesting there were distinction of bacterial community structure in different treatments. Additionally, Ralstonia were significant higher in CK treatment than the other treatments. While Granulicella, Hyphomicrobium, Haliangium, Nitrospira, Sphingoblum were more abundant in the T1 treatment than the other treatments.

Fungal diversity and community structure in soil. All rhizosphere soil samples consist of 31,663 highquality raw sequences for fungal. The difference of the OTUs, Chaol and Shannon index of fungal community among treatment groups were also analyzed (Table S2). The OTUs, Chao1 and Shannon index were also higher in the T1 treatment group than in the other treatment groups during all stages of tobacco growth. Thereby, the T1 treatment group has a higher fungal diversity and richness than the other treatment groups. Six main known fungal phyla were identified from all soil samples, including Ascomycota (15.0-56.0\%), followed by Mortierellomycota (4.0-26.0\%), Basidiomycota (1.0-12.3\%), Olpidiomycota (3.0-6.4\%), Mucoromycota (0-3.8\%) and Chytridiomycota (0.6\%) (Fig. 2a). Overall, the total relative abundance of six fungal phyla was low at 50 days, and increased at 70 days, while different fungal phyla varied irregularly, suggesting fungal phyla changed during different tobacco growth stages. According to PCA analysis, PC1 and PC2 explained 59.07\% of the total fungal community (Fig. 2b). The fungal community of different treatments was separated from each other, and different tobacco growth stages within one treatment showed close distances, indicating different treatments had influence on fungal community. In the Heatmap for fungal community structure (Fig. 2c), four broad categories were divided, and the antagonistic fungal (such as Curvularia, Trichoderma, Scutellospora, Aspergillus) were more abundant in the T1 treatment than the other treatments.

The relative abundance of $\boldsymbol{R}$. Solanacearum. The relative abundance of $R$. solanacearum in the rhizosphere soil of different treatment groups at different tobacco growth periods were analyzed. The variation trend of the relative abundance of $R$. solanacearum in different treatment groups was similar. The relative abundance of $R$. solanacearum increased from 50 to 70 days and decreased from 70 to 90 days. From 50 to 90 days posttransplantation, the relative abundance of $R$. solanacearum in the CK was significantly higher than other treatment groups. Additionally, the relative abundance of $R$. solanacearum in the T1 group was the lowest among all treatment groups (Fig. 3).

Soil metabolites from different treatments. GC-TOF-MS analysis of $80 \%(\mathrm{v} / \mathrm{v})$ methanol crude extracts resulted in identification of 46 features were identified in all soil samples. PCA was applied to understand the clustering features of different treatments soil metabolites at different tobacco growth periods. The first components (PC1) showed 30.09\% difference in variation, and PC2 explained $21.12 \%$ of the variance (Fig. $4 \mathrm{a}$ ). 
a

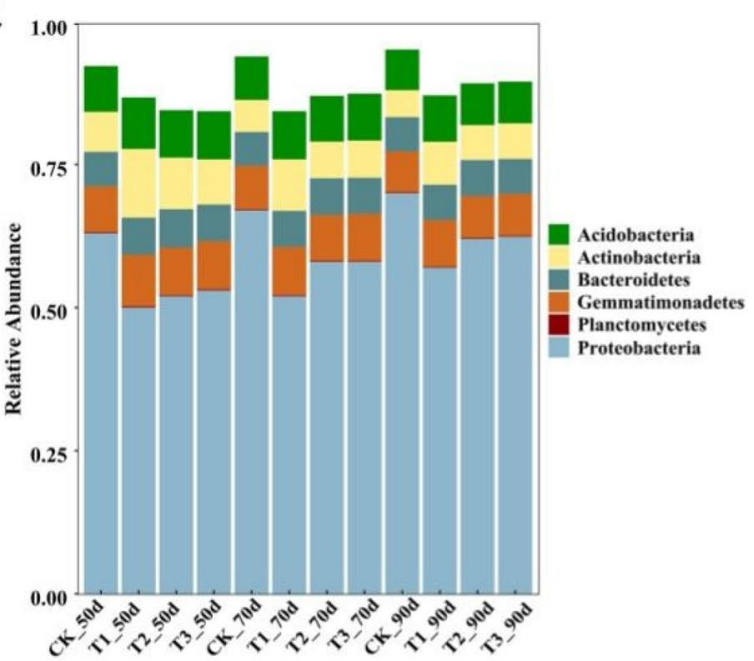

b

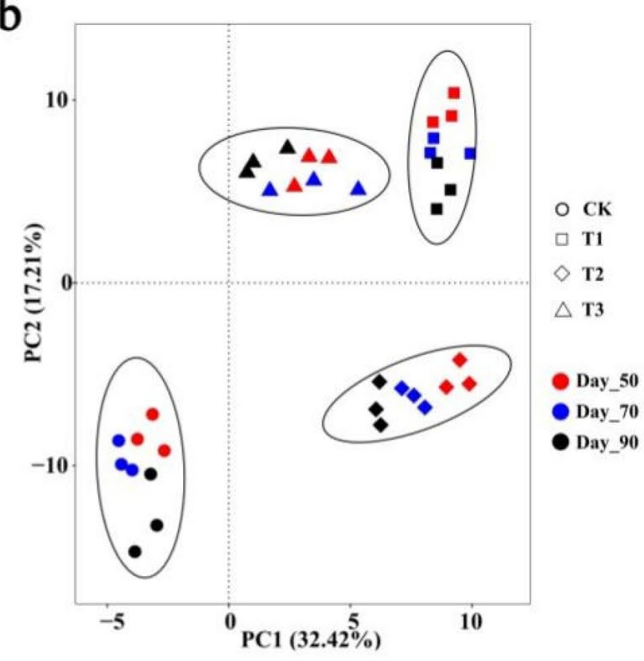

c

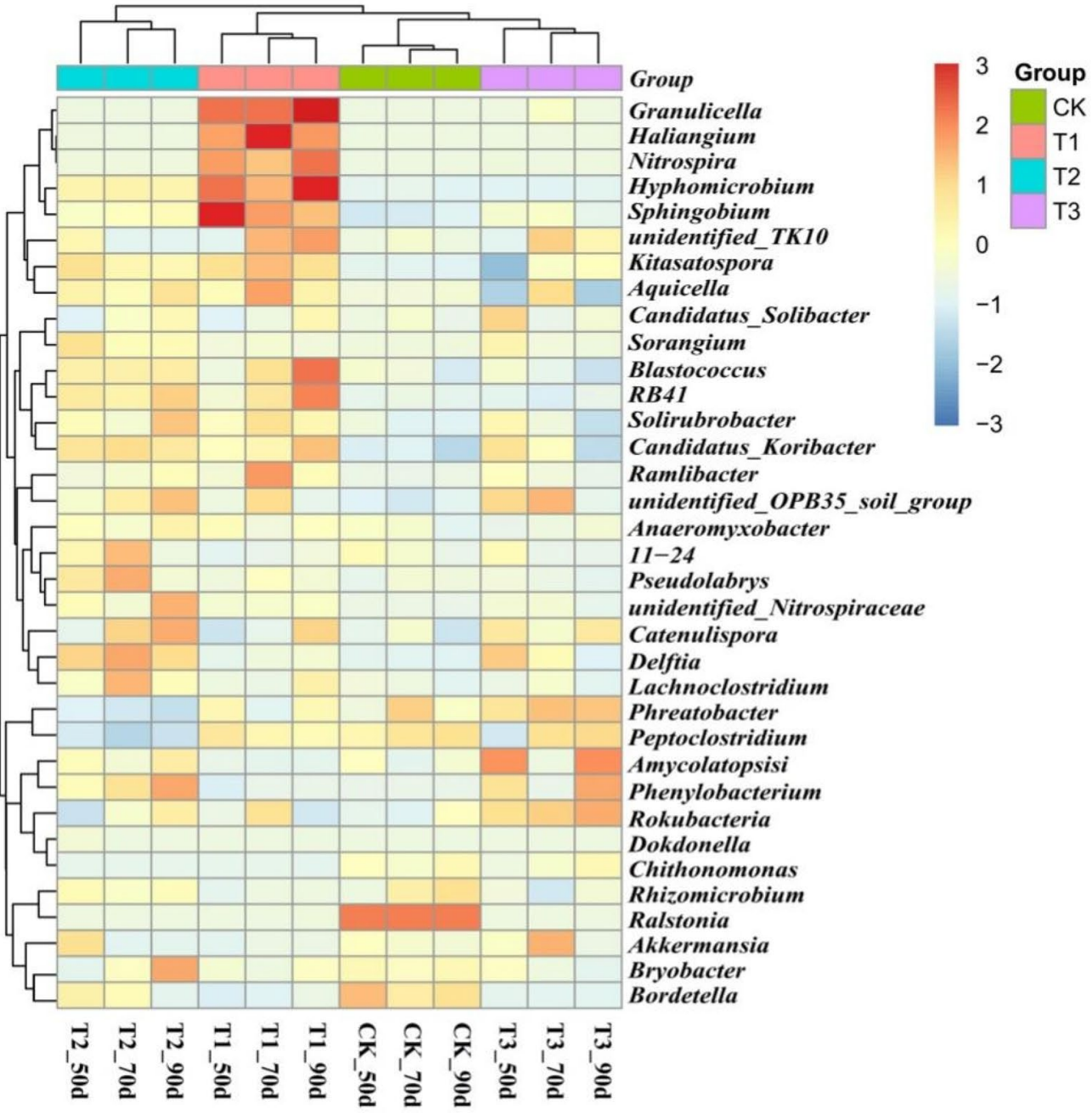

Figure 1. Soil bacterial community in four treatments at 50 days, 70 days and 90 days post-transplanted, respectively. (a) The relative abundance of bacterial phyla in soil samples. (b) The Principal components analyzed (PCA) of soil bacterial community. (c) Hierarchical cluster analysis of predominant bacterial genera. (CK: the control group, T1: marigold powder mix with B. amyloliquefaciens ZM9 group, T2: B. amyloliquefaciens ZM9 group, T3: marigold powder). 
a

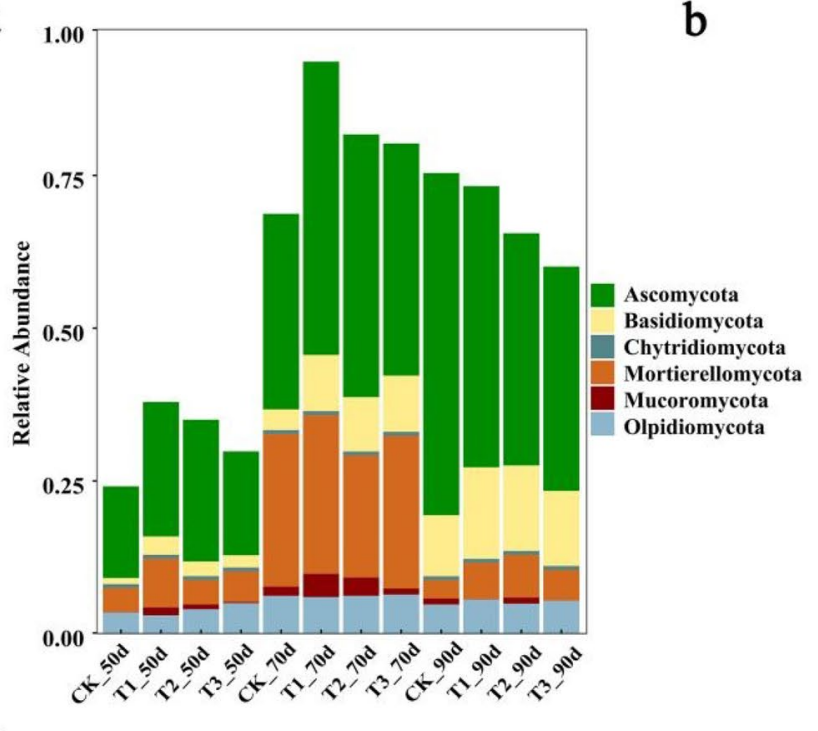

C

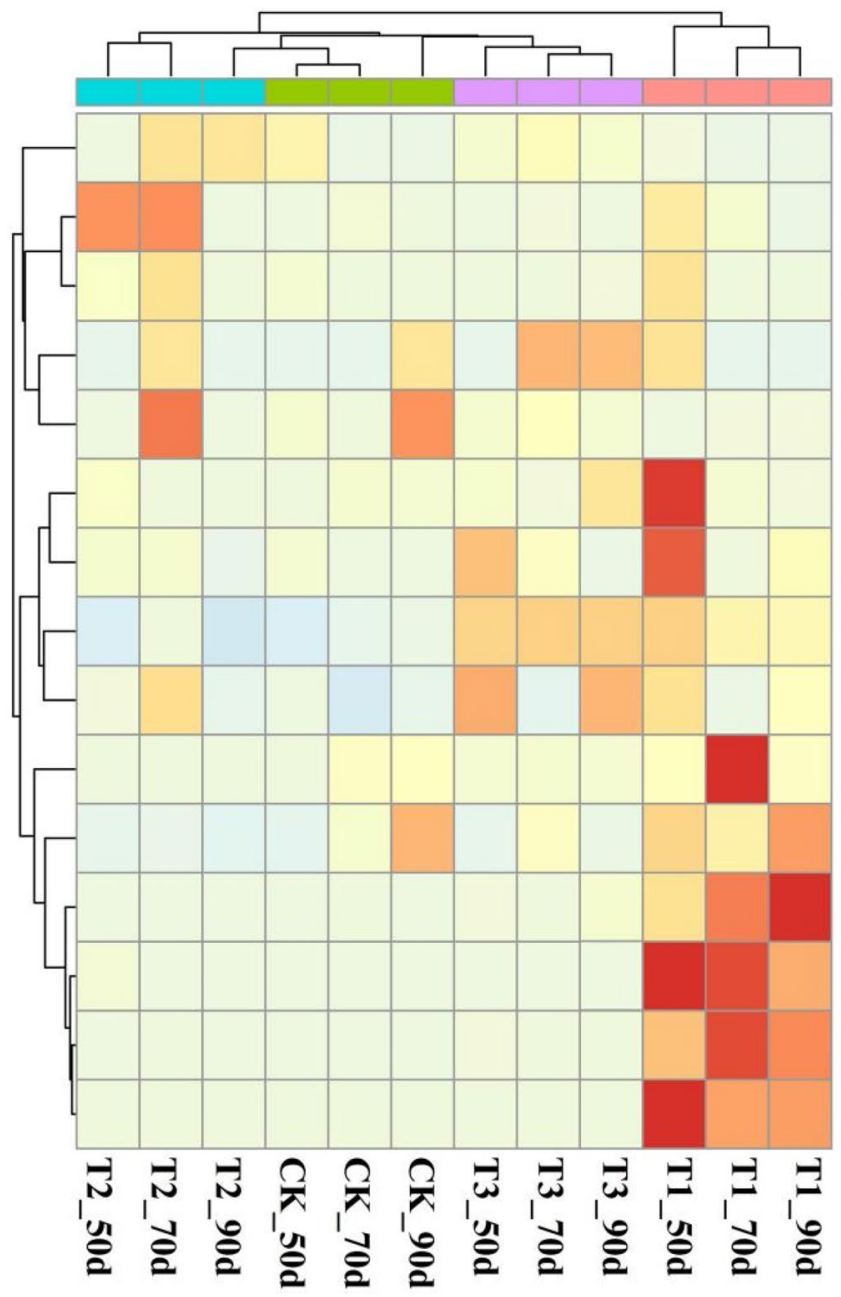

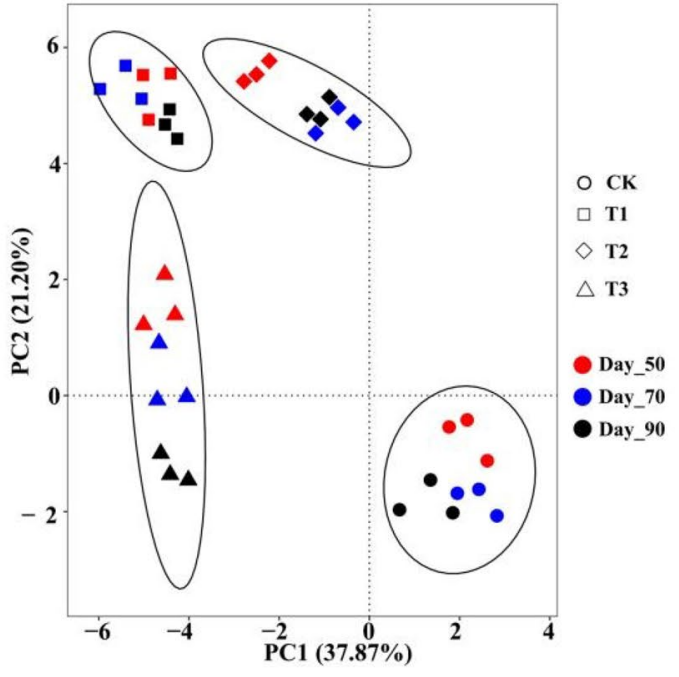

Group

Chaetomium

Melanconium

Rhizopus

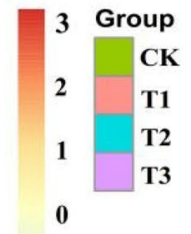

Pseudeurotium

Papulaspora

Mortierella

Mortierellomycota

Gigaspora

\section{Trichocladium}

\section{Myrothecium}

\section{Xanthoria}

\section{Scutellospora}

\section{Trichoderma}

Curvularia

Aspergillus

Figure 2. Soil fungal community in four treatments at $50 \mathrm{~d}, 70 \mathrm{~d}$ and $90 \mathrm{~d}$ post-transplanted, respectively. (a) The relative abundance of fungal phyla in soil samples. (b) Hierarchical cluster analysis of predominant fungal genera. (c) The Principal components analyzed (PCA) of soil fungal community. (CK: the control group, T1: marigold powder mix with B. amyloliquefaciens ZM9 group, T2: B. amyloliquefaciens ZM9 group, T3: marigold powder). 


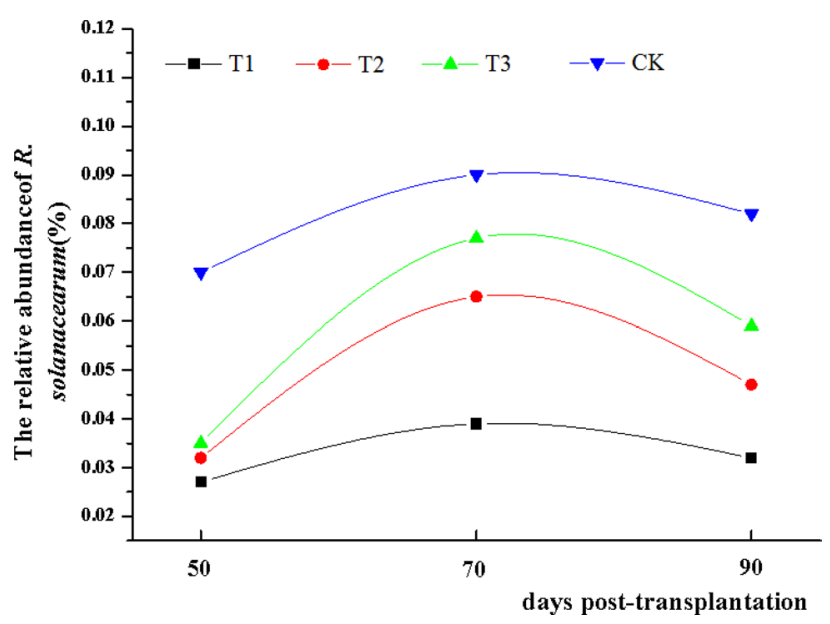

Figure 3. The relative abundance of $R$. solanacearum in rhizosphere soil from four treatments at 50 days, 70 days and 90 days post-transplanted, respectively. CK: the control group, T1: marigold powder mix with $B$. amyloliquefaciens ZM9 group, T2: B. amyloliquefaciens ZM9 group, T3: marigold powder.

a

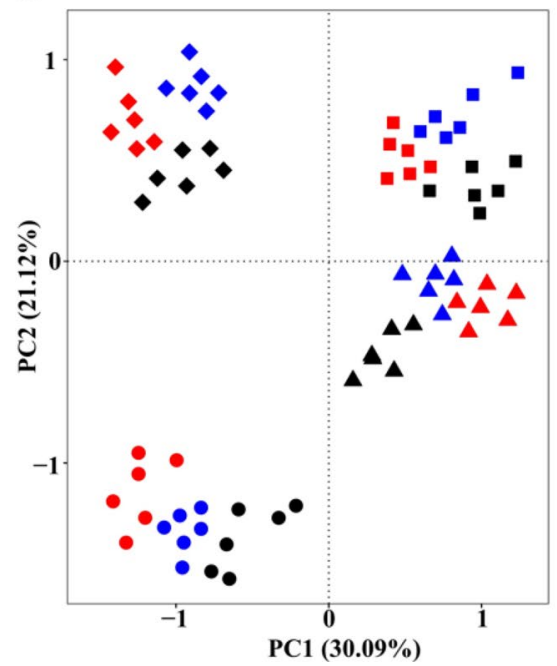

b

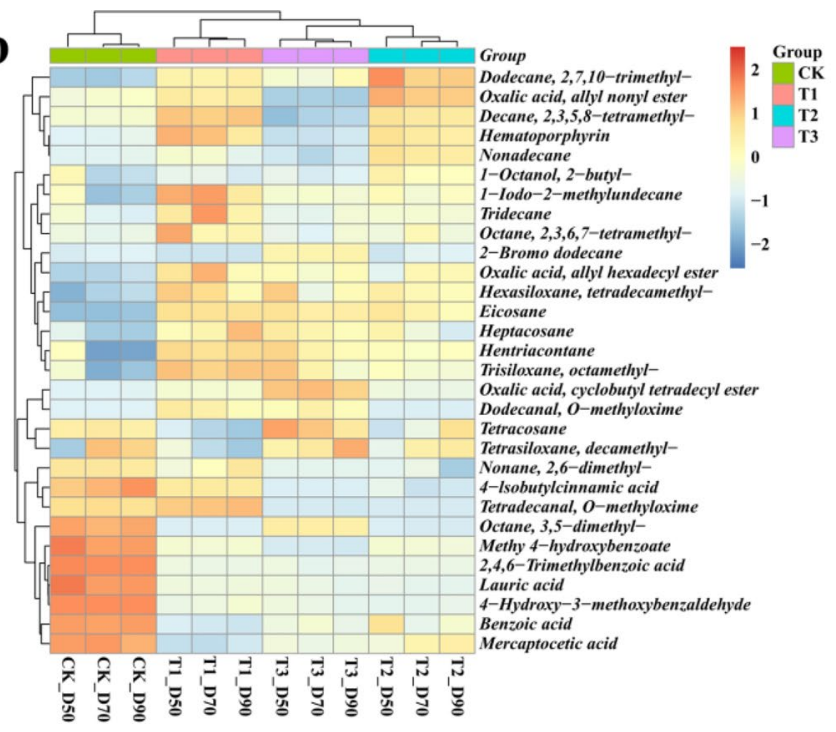

Figure 4. (a) Principal component analysis (PCA) of metabolites analyzed from the four treatments soil at 50 days, 70 days and 90 days post-transplanted, respectively. (b) Heatmap showing top 30 most significant metabolites from soil samples of four treatments at 50 days, 70 days and 90 days post-transplanted. (CK: the control group, T1: marigold powder mix with B. amyloliquefaciens ZM9 group, T2: B. amyloliquefaciens ZM9 group, T3: marigold powder).

Different treatments were respectively clustered together and separated from each other, indicating different treatments play impact on soil metabolites. The Heatmap detailed the soil metabolites concentration of different treatments based on the top 30 significant metabolites (Fig. 4b). The concentration of benzoic acid, lauric acid, 4-hydroxy-3-methoxybenzaldehyde, methyl 4-hydroxybenzoate and mercaptoacetic acid were obviously higher in the CK than those in the other treatments.

Relationships among microbial community, soil physicochemical properties and metabolites. Canonical correspondence analysis (CCA) was used to investigate the relationships among microbial community, soil physicochemical properties and metabolites. Eleven factors including $\mathrm{pH}, \mathrm{HN}, \mathrm{AP}, \mathrm{AK}$, benzoic acid, lauric acid, 4-hydroxy-3-methoxybenzaldehyde, methyl 4-hydroxybenzoate, 4-Isobutylcinnamic acid, 2,4,6-trimethylbenzoic acid and mercaptoacetic acid were selected for CCA. The results showed that the treatments of T1, T2, T3 and CK were separated from each other (Fig. 5). These variables explained $65.81 \%$ and $64.79 \%$ of bacterial and fungal community variation, respectively. The bacterial community composition in the $\mathrm{T} 1$ group were positively correlated with $\mathrm{pH}, \mathrm{AK}$ and $\mathrm{AP}$, but negatively correlated with $\mathrm{HN}$, 4-hydroxy-3-methoxybenzaldehyde, benzoic acid, methyl 4-hydroxybenzoate, lauric acid, 2,4,6-trimethylbenzoic acid, 4-isobutylcinnamic acid and mercaptoacetic acid. While the bacterial community composition in the CK group were 
a

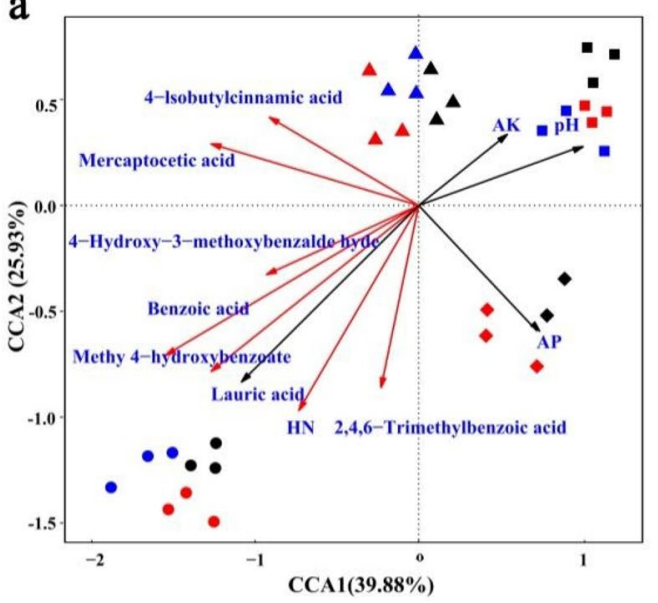

b

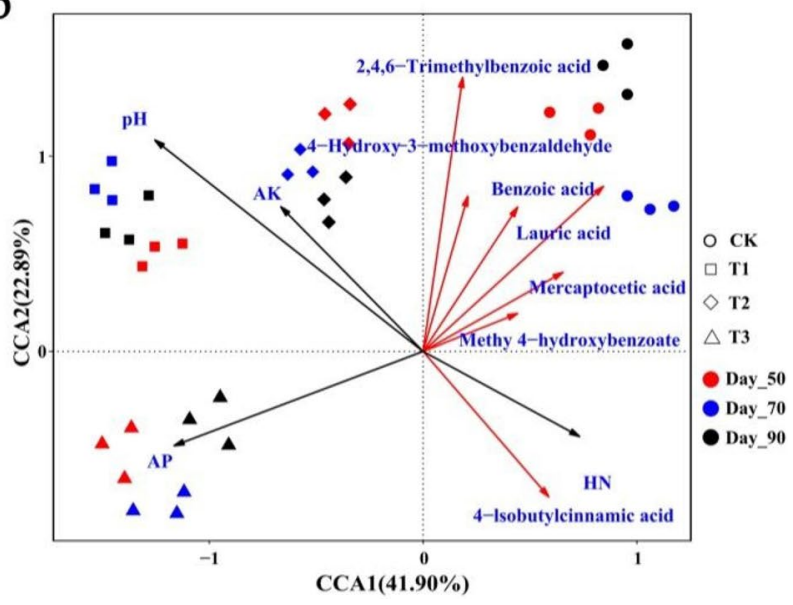

Figure 5. Canonical correspondence analysis (CCA) of the relative abundance of microbial community with soil physicochemical properties and metabolites. (a) Soil bacterial community, (b) soil fungal community. The soil properties and metabolites are indicated with arrows, including soil pH, hydrolysable nitrogen $(\mathrm{HN})$, available phosphorous (AP), available potassium (AK), benzoic acid, lauric acid, 4-hydroxy-3methoxybenzaldehyde, methyl 4-hydroxybenzoate, 4-Isobutylcinnamic acid, 2,4,6-trimethylbenzoic acid and mercaptoacetic acid. CK: the control group, T1: marigold powder mix with B. amyloliquefaciens ZM9 group, T2: B. amyloliquefaciens ZM9 group, T3: marigold powder. The percentage of variation is explained by each axis.

positively correlated with $\mathrm{HN}$, 4-hydroxy-3-methoxybenzaldehyde, benzoic acid, methyl 4-hydroxybenzoate, lauric acid, 2,4,6-trimethylbenzoic acid and mercaptoacetic acid (Fig. 5a). For fungi, the fist canonical axis was positively correlated with 2,4,6-trimethylbenzoic acid, 4-hydroxy-3-methoxybenzaldehyde, lauric acid, benzoic acid, mercaptoacetic acid and methyl 4-hydroxybenzoate, the second axis was positively correlated with $\mathrm{pH}$ and AK (Fig. 5b). As important variables, pH, AK, AP, HN, benzoic acid, lauric acid, mercaptoacetic acid and 4-hydroxy-3-methoxybenzaldehyde played major roles in the shaping of soil microbial community.

\section{Discussion}

In our previous study, B. amyoliquefaciens ZM9 as an efficient biocontrol agent can reduce TBW by producing lipopeptides to against $R$. solanacearum and changing the tobacco rhizosphere microbial community ${ }^{13}$. Marigold is reported to have antibacterial activity, and effectively reduce the incidence of $\mathrm{TBW}^{18,20}$. The application of single biocontrol agent is difficult to perform sustainable and efficient against pathogens of the plant under diverse soil environmental conditions. Hence, antibacterial plant assistance of antagonistic bacteria should be considered as an effective integrated biocontrol method to improve the colonization ability of antagonistic bacteria and control bacterial wilt. In order to achieve more sustainable and efficient control, we applied B. amyloliquefaciens ZM9 and marigold powder to tobacco fields in different ways. We have demonstrated that B. amyloliquefaciens ZM9 and marigold power had potential for controlling bacterial wilt. Furthermore, the combination of B. amyloliquefaciens ZM9 and marigold power could more effective suppress TBW than single application of B. amyloliquefaciens ZM9 or marigold. The integrated biocontrol method significantly suppressed TBW through changing soil chemical properties, rhizosphere microbial community and soil metabolites.

Hooks et al. (2010) summaried that the mechanism of marigold inhibiting nematodes includes enhancing the activity of antagonistic microorganisms ${ }^{17}$. Our study also found that marigold powder could promote antagonistic bacteria B. amyloliquefaciens ZM9 (Fig S1). Terblanche and De Villiers (1998) showed that marigold not only reduced the pathogen population in the soil, but also prevented the tobacco plants from developing symptoms ${ }^{22}$. In our present study, the application of marigold powder reduced the TBW incidence and index (Table 1), which was consistent with previous study ${ }^{22}$. In addtion, the combination of B. amyloliquefaciens ZM9 and marigold powder significantly reduced the disease incidence and index compared with single application of B. amyloliquefaciens ZM9 or marigold powder (Table 1). This consistent with some researches which indicated that the application of biocontrol agents alone is unlikely to perform consistently on plant pathogens in different rhizosphere soil environments. While, the integrated biocontrol method is more effective in reducing the disease incidence and index of bacterial wilt, and this could be attributed to different mechanisms in disease suppression or competition for nutrients $\mathrm{s}^{21,23-25}$.

Several studies have demonstrated that increasing $\mathrm{pH}$ is important for inhibiting the survival of $R$. Solanacearum, and soil $\mathrm{pH}$ as an environmental factor can regulate the soil physicochemical properties, metabolites and microbial community composition ${ }^{20,26-28}$. Nutrient $\mathrm{P}$ has also been reported to meet the need of plant growth and increase the soil microbial diversity, and the increased P supply significantly decreased the relative density of $R$. Solanacearum ${ }^{29,30}$. In this study, rhizosphere soil properties $\mathrm{pH}, \mathrm{AP}$ and $\mathrm{AK}$ were negatively correlated with the incidence of TBW. Additionally, the T1 (B. amyloliquefaciens ZM9 mix with marigold powder group) had a higher $\mathrm{pH}$ value, $\mathrm{AP}$ and $\mathrm{AK}$ content than other treatments, consistently with previous report ${ }^{29}$. We infer that the integrated application of B. amyloliquefaciens ZM9 and marigold powder may reduce the incidence of TBW by changing soil physicochemical properties. 
In the current study, the OTUs, Chaol and Shannon index of soil microbial community were higher in the T1 treatment than in the other treatments, indicating the integrated application of B. amyloliquefaciens ZM9 and marigold powder could improve the richness and diversity of microbial community. In addition, the soil microbial community varies at different tobacco growth stages. The results of PCA, suggesting different treatments and growth stages could influence soil microbial community structure, which was similar to previous report $^{20,31}$. It was also testified by the Heatmap, showing the difference of microbial community structure in different treatments. Moreover, Granulicella, Hyphomicrobium, Haliangium, Nitrospira, Sphingoblum, Curvularia, Trichoderma, Scutellospora, Aspergillus were more abundant in the T1 treatment. Previously reports showed that most of these genera have beneficial effects on soil nutrient cycling, the genera Hyphomicrobium and Nitrospira played important role in nitrogen cycling ${ }^{32,33}$. Granulicella was found to use different substances as carbon sources and participate in carbon cycling in the soil ${ }^{34}$. Besides, Haliangium and Sphingoblum was reported as beneficial rhizosphere microorganisms can mitigate many soil-borne diseases and assist plant growth by increasing plant health and growth ${ }^{35,36}$. The antagonistic microorganisms Trichoderma, Scutellospora and Aspergillus were reported to interact directly with roots to produce bioactive substances that promote plant growth and resist biotic and abiotic stress ${ }^{37,38}$. In accordance with other researches, the inhibition of bacterial wilt could not be attributed to a single bacterial or fungal group, and this inhibition is most likely governed by microbial consortia networks ${ }^{39,40}$. Results also showed that the relative abundance of $R$. solanacearum in the T1 groups was the lowest among all treatment groups. Therefore, the integrated application of B. amyloliquefaciens ZM9 and marigold powder can affect soil microbial community and rebuild healthy soil microbial community composition to against tobacco plants from pathogen infection.

Soil metabolomics could provide insight into the complex interactions of plants, soil and microorganisms ${ }^{41-43}$. According to the previous investigation, the occurrence of soil-borne disease is closely related with root exudates $^{44}$. Some studies have also found that organic acids benzoic acid and lauric acid from tobacco root exudates can simulate the growth of $R$. solanacearum ${ }^{45,46}$. Phenolic acid 4-hydroxy-3-methoxybenzaldehyde as allelochemical with high concentration can inhibit the growth of plant and promote the occurrence of soil-born disease $^{47,48}$. Hasegawa et al. (2019) showed several aromatic acid secreted by plants are chemoattractants of $R$. Solanacearum $^{49}$. In our study, metabolites benzoic acid, lauric acid, 4-hydroxy-3-methoxybenzaldehyde and mercaptoacetic acid were found notably higher in the CK group and lower in T1 treatment, consistent with the previous findings ${ }^{45-48}$. On the other hand, Terblanche and De Villiers (1998) demonstrated that the secondary metabolites of marigold could inhibit R. Solanacearum. Therefore, the integrated application of B. amyloliquefaciens ZM9 and marigold powder may reduce the incidence of bacterial wilt by regulating root exudates ${ }^{22}$. Metabolomic analysis of the soil studied indicated a separation among different treatment during different tobacco growth stages. The content of soil metabolites increased with the growth of tobacco, which was probably due to the accumulation of root exudates. Furthermore, the content of root exudates increased at different tobacco growth stages, which had a great impact on soil microbial community.

After CCA, the relationships among microbial community, soil physicochemical properties and metabolites showed that $\mathrm{pH}, \mathrm{AK}, \mathrm{AP}, \mathrm{HN}$, benzoic acid, lauric acid, mercaptoacetic acid and 4-hydroxy-3-methoxybenzaldehyde played major roles in the shaping of soil microbial community. In accordance with other studies, soil physicochemical properties related to the microbial community structure, and high $\mathrm{pH}$ and AP has been linked to a higher abundance of microbial ${ }^{31}$. Besides, some metabolites were also correlated with microbial abundance $\mathrm{e}^{50}$. Therefore the changes of soil microbial community at different tobacco growth stages was possibly due to the changes of soil metabolites and soil physicochemical properties ${ }^{31,49}$.

\section{Conclusions}

Application of antagonistic bacteria B. amyloliquefaciens ZM9 or antibacterial plant marigold powder alone showed effective biocontrol of TBW. The integrated application of a combination of B. amyloliquefaciens ZM9 and marigold powder showed more effectiveness in suppressing TBW than application of either B. amyloliquefaciens ZM9 or marigold power alone. B. amyloliquefaciens ZM9 and marigold have synergistic effects suppressed TBW by regulation soil physicochemical properties, microbial structure and soil metabolites. Our results provide a promising strategy for TBW control by integrated applying of B. amyloliquefaciens ZM9 and marigold powder.

\section{Materials and methods}

Field experiment. The field experiment was carried out in a continuous cropping tobacco field in Xuan'en County $\left(109.26^{\circ} \mathrm{E}, 29.59^{\circ} \mathrm{N}\right)$, Enshi City, Hubei province, China from April to September 2019. The field experimental was carried out according to the rules of flue-cured tobacco cultivation (GB/T 23221-2008). The field, $480 \mathrm{~m}^{2}$ in size, and the incidence of TBW was higher than $95 \%$ every year for the past five years. Tobacco seeds of Yunyan 87 were provided by the Tobacco Research Institute of Hubei, Wuhan, China. The seeds were grown in floating polystyrene trays in a greenhouse for approximately 60 days before being transplanted to the field. $5 \mathrm{~g}$ compound fertilizer, $10 \mathrm{~g}$ potassium phosphate, $450 \mathrm{~g}$ ash soil and $50 \mathrm{~g}$ tobacco straw fertilizer were applied to each tobacco plant when transplantation ${ }^{13}$. B. amyloliquefaciens ZM9 (Genbank: KF906355.1) was used as the antagonistic bacteria in this study. The roots and stems of marigold discarded by local farmers were collected, air-dried, smashed and filtered for 20 mesh as marigold powder. The experimental design consisted of three blocks, each $160 \mathrm{~m}^{2}$ in size, each block was divided into four plots of $40 \mathrm{~m}^{2}, 60$ plants in each plots. Four treatments: (1) the control group (CK, without any pesticide); (2) B. amyloliquefaciens ZM9 mix with marigold powder group (T1): B. amyloliquefaciens ZM9 was incubated as previous study ${ }^{51}, 1 \mathrm{~g}$ of marigold powder was mixed with the $100 \mathrm{~mL}$ of $B$. amyloliquefaciens $\mathrm{ZM} 9$ culture $\left(1.0 \times 10^{7} \mathrm{CFU} / \mathrm{mL}\right)$ and then irrigated into the tobacco roots when transplantation. The effect of marigold powder on B. amyloliquefaciens ZM9 was evaluated by the plate count method ${ }^{13}$ (Fig. S1); (3) B. amyloliquefaciens ZM9 group (T2): $100 \mathrm{~mL}$ of B. amyloliquefaciens ZM9 
culture $\left(1.0 \times 10^{7} \mathrm{CFU} / \mathrm{mL}\right)$ irrigated into the tobacco roots when transplantation; and (4) marigold powder group (T3): $1 \mathrm{~g}$ of marigold powder was applied to the tobacco roots when transplantation. The planting density of all treatments were the same, and all treatments and replicates were randomly placed in the field.

Rhizosphere soil sampling and physicochemical properties analysis. Rhizosphere soil were collected by five-spot-sampling method at 0 days, 50 days, 70 days and 90 days post-transplantation when recording the disease occurrence. Then the soil samples from the five separate sites were mixed to one soil sample, and partitioned into two subsamples, one stored at $-80^{\circ} \mathrm{C}$ for microbiological and metabolome analysis, and another for physicochemical properties analysis after air-dry. The analysis of soil $\mathrm{pH}$, hydrolysable nitrogen $(\mathrm{HN})$, available phosphorous (AP) and available potassium (AK) was performed according to previous study ${ }^{52}$.

Disease incidence and index. At $50 \mathrm{~d}, 70 \mathrm{~d}$ and $90 \mathrm{~d}$ post-transplantation, the symptoms of TBW were monitored at five different sites. The TBW disease index (DI) based on severity scale of 0-9 was described in a previous studies ${ }^{14,53}$. Briefly, "0" represents the plants without visible symptoms; " 1 " represents the presence of occasional chlorotic spots on stems, or less than half of the leaves wilted on unilateral stems; " 3 " represents the presence of a black streak less than half the height of the stem, or between half to two-thirds of the leaves wilted on unilateral stems; " 5 " represents the presence of a black streak over half the length of the stem, but not reaching the top of the stem, or more than two-thirds of the leaves wilted on unilateral stems; "7" represents the presence of a black streak reaching the top of the stem, or all leaves wilted; and "9" represents the dead plant. Based on the number of plants in each rating scale, disease incidence (I) and disease index (DI) of TBW were calculated as $\mathrm{I}=\mathrm{n}^{\prime} / \mathrm{N} \times 100 \%$ and $\mathrm{DI}=\Sigma(\mathrm{r} \times \mathrm{n}) /(\mathrm{N} \times 9) \times 100$, where $\mathrm{n}^{\prime}$ is the total number of infected tobacco plants, $\mathrm{r}$ is the rating scale of disease severity, $\mathrm{n}$ is the number of infected tobacco plants with a rating of $\mathrm{r}$, and $\mathrm{N}$ is the total number of plants.

Soil DNA extraction. Soil DNA was extracted from $0.5 \mathrm{~g}$ rhizosphere soil using the FastDNA Spin Kit (MP Biomedicals, USA), following the manufacture's protocol. The integrity of DNA samples were determinde by $1 \%$ agarose gel electrophoresis. Then the concentration and purity of the DNA were determined using a Nanodrop ND-1000 Spectrophotmeter (Nanodrop Techenologies, USA) ${ }^{14}$.

DNA sequence data collection and analysis. The extracted soil genomic DNA was used as template to amplify $16 \mathrm{~S}$ rRNA and ITS rRNA genes according to our previous study ${ }^{14}$. The V4 regions of $16 \mathrm{~S}$ rRNA gene were amplified using primers 515F (5' GTGCCAGCMGCCGCGGTAA 3') and 806R (5' GGACTACHVGGG TWTCTAAT 3' $)^{13}$, while the ITS1 regions of ITS rRNA gene were amplified using primers ITS5-1737F (5'-GGA AGTAAAAGTCGTAACAAGG-3') and ITS2-2043R (5'-GCTGCGTTCTTCATCGATGC-3' ${ }^{26}$. The library was sequenced on an Illumina HiSeq platform (Novogene Bioinformatics Technology Co., Ltd, China). The sequence quality was statistically analyzed by CASAVA1.8. The raw sequence data was preliminarily filtrate using the FASTX Toolkit 0.0.13 software package, removing the low mass base at the tail of the sequence (Q value less than 20) and the sequences with lengths less than $35 \mathrm{bp}$. Finally, the length of the valid reads was approximately $250 \mathrm{bp}$. All effective tags of all samples were clustered using Uparse software (V7.0.1001, http:// drive 5.com/uparse/). Sequences with $\geq 99.5 \%$ identity for $16 \mathrm{~S} \mathrm{rDNA}$ and sequences with $\geq 97 \%$ identity for ITS were assigned to the same OTUs (operational taxonomic units). The OTUs, Chaol and Shannon index were calculated with QIIME (Version 1.7.0) to evaluate richness and diversity of soil microbial community. The principal components analyzed (PCA) with the weighted Unifrac distance was carried out using software R (R Core Team 2014).

Soil metabolite extraction. The ground soil ( $1 \mathrm{~g})$ was extracted in $5 \mathrm{~mL} 80 \%(\mathrm{v} / \mathrm{v})$ methanol ( $10 \mathrm{~min}$, $20^{\circ} \mathrm{C}$ ) using sonicator. The residue was reextracted twice with the same procedure and the total combined supernatant was filtered through Whatman filter paper $(125 \mathrm{~mm})$. The supernatant was dried in a vacuum concentrator without heating. The extracts obtained were stored at $-80{ }^{\circ} \mathrm{C}$ for GC-TOF-MS analysis ${ }^{54}$.

GC-TOF-MS analysis and data preprocessing. The dried extracts were added to $60 \mu \mathrm{L}$ of a methoxyamination hydrochloride in pyridine $\left(20 \mathrm{mg} \mathrm{mL}^{-1}\right)$, and incubated at $80{ }^{\circ} \mathrm{C}$ for $30 \mathrm{~min}$, for methoxymation. Then, $80 \mu \mathrm{L}$ of the BSTFA regent (1\% TMCS, v/v) was added, and resulting solutions were incubated at $70{ }^{\circ} \mathrm{C}$ for $1.5 \mathrm{~h}$. All samples were analyzed by gas chromatograph system coupled with a Pegasus HT time-of-flight mass spectrometer (GC-TOF-MS) ${ }^{55}$.

GC-TOF-MS analysis was performed using an Agilent 7890 gas chromatograph system (Agilent Technologies Inc., USA) coupled with a Pegasus HT time-of-flight mass spectrometer (LECO Corporation, USA). The system utilized a DB-5MS capillary column $(30 \mathrm{~m}$, i.d. $250 \mu \mathrm{m}$, and film thickness $0.25 \mu \mathrm{m}$; Agilent Technologies Inc., USA), was employed, applying positive electron ionization $(70 \mathrm{eV})$. Full-scan mode were acquired over the 50-500 Da mass (scan rate of 12.5 scans per second) applying a solvent delay of $4.78 \mathrm{~min}$. The injection, transfer line, and ion source temperatures were 280,280 , and $250^{\circ} \mathrm{C}$, respectively. The samples $(1 \mu \mathrm{L})$ were injected in splitless mode. Helium was used as the carrier gas, the front inlet purge flow was $3 \mathrm{~mL} \mathrm{~min}{ }^{-1}$, and the gas flow rate through the column was $1 \mathrm{~mL} \mathrm{~min}{ }^{-1}$. The initial temperature of the oven was $50{ }^{\circ} \mathrm{C}$ for $1 \mathrm{~min}$, raised at a rate of $20^{\circ} \mathrm{C} \min ^{-1}$ to $310^{\circ} \mathrm{C}$, then kept for $6 \mathrm{~min}$ at $310^{\circ} \mathrm{C}^{55}$.

Chroma TOF 4.3X software (LECO Corporation, USA) and the LECO-Fiehn Rtx 5 database were used for raw peaks exacting, data baselines filtering and calibration, peak alignment, deconvolution analysis, peak 
identification and integration of the peak area. Both of mass spectrum match and retention index match were considered in metabolites identification.

Statistical analysis. Differences between treatment groups were assessed by one-way analysis of variance (ANOVA) and least significant difference (LSD) test $(\mathrm{p}<0.05)$. Correlation analysis between disease incidence of TBW and soil physicochemical properties was conducted by Pearson (2-tailed). Heatmaps analyses based on soil microbial community were generated using software R (R Core Team 2014). Canonical correspondence analysis (CCA) used software R (R Core Team 2014) to analyze the relationships among microbial community structure, soil physicochemical properties and metabolites.

Received: 4 February 2021; Accepted: 27 July 2021

Published online: 11 August 2021

\section{References}

1. Yuliar, N. Y. A. \& Toyota, K. Recent trends in control methods for bacterial wilt diseases caused by Ralstonia solanacearum. Microbes Environ. 30, 1-11 (2015).

2. Hayward, A. C. Biology and epidemiology of bacterial wilt caused by Pseudomonas solanacearum. Annu. Rev. Phytopathol. 29, 65-87 (1991).

3. Gamliel, A., Austerweil, M. \& Kritzman, G. Non-chemical approach to soilborne pest management-Organic amendments. Crop Protect. 19, 847-853 (2000).

4. Bai, W., Kong, F., Lin, Y. \& Zhang, C. Extract of Syringa oblata: A new biocontrol agent against tobacco bacterial wilt caused by Ralstonia solanacearum. Pestic. Biochem. Phys. 134, 79-83 (2016).

5. Grosch, R. et al. Biocontrol of Rhizoctonia solani: Complex interaction of biocontrol strains, pathogen and indigenous microbial community in the rhizosphere of lettuce shown by molecular methods. Plant Soil. 361, 343-357 (2012).

6. Alabouvettec, C., Olivain, C., Migheli, Q. \& Steinberg, C. Microbiological control of soil-brone phytopathogenic fungi with special emphasis on wilt-inducing Fusarium oxysporum. New Phytol. 184, 529-544 (2009).

7. Igiehon, N. O. \& Babalola, O. O. Biofertilizers and sustainable agriculture: Exploring arbuscular mycorrhizal fungi. Appl. Microbiol. Biot. 101, 4871-4881 (2017).

8. Pal, K. K., Tilak, K., Saxcna, A. K., Dey, R. \& Singh, C. S. Suppression of maize root diseases caused by Macrophomina phaseolina, Fusarium moniliforme and Fusarium graminearum by plant growth promoting rhizobacteria. Microbiol. Res. 156, 209-223 (2001).

9. Wang, X. \& Liang, G. Control efficacy of an endophytic Bacillus amyloliquefaciens strain BZ6-1 against peanut bacterial wilt Ralstonia solanacearum. Biomed. Res. Int. 2014, 1-11 (2014).

10. Bubici, G., Marsico, A. D., D’Amico, M., Amenduni, M. \& Cirulli, M. Evaluation of Streptomyces spp. for the biological control of corky root of tomato and Verticillium wilt of eggplant. Appl. Soil Ecol. 72, 128-134 (2013).

11. Emmert, E. A. \& Handelsman, J. Biocontrol of plant disease: A (Gram-) positive perspective. FEMS Microbiol. Lett. 171, 1-9 (1999).

12. Baysal, Ö. et al. A proteomic approach provides new insights into the control of soil-borne plant pathogens by Bacillus species. PLOS ONE 8, e53182 (2013).

13. Wu, B. et al. Effects of Bacillus amyloliquefaciens ZM9 on bacterial wilt and rhizosphere microbial community of tobacco. Appl. Soil Ecol. 103, 1-12 (2016).

14. Hu, Y. et al. Effects of integrated biocontrol on bacterial wilt and rhizosphere bacterial community of tobacco. Sci. Rep. 11, 2653 (2021).

15. Van Rij, E. T., Wesselink, M., Chin-A-Woeng, T. F. C., Bloemberg, G. V. \& Lugtenberg, B. J. J. Influence of environmental conditions on the production of phenazine-1-carboxamide by Pseudomonas chlororaphis PCL1391. Mol. Plant Microbe Int. 17, 557-566 (2004).

16. Gómez-Rodriguez, O., Zavaleta-Mejia, E., Gonzalez-Hernandez, V. A., Livera-Muñoz, M. \& Cárdenas-Soriano, E. Allelopathy and microclimatic modification of intercropping with marigold on tomato early blight disease development. Field Crop. Res. 83, 27-34 (2003).

17. Hooks, C. R. R., Wang, K. H., Ploeg, A. \& McSorley, R. Using marigold (Tagetes spp.) as a cover crop to protect crops from plantparasitic nematodes. Appl. Soil Ecol. 46, 307-320 (2010).

18. Xie, G. H. et al. Crop rotation and intercropping with marigold are effective for root knot nematode (Meloidogyne sp.) control in angelica (Angelica sinensis) cultivation. Can. J. Plant Sci. 97, 26-31 (2017).

19. Terblanche, J. Biological Control of Bacteria Wilt in Tobacco Caused by Ralstonia solanacearum (University of the Free State, 2007).

20. Li, Y. Y. et al. Intercropping with marigold promotes soil health and microbial structure to assist in mitigating tobacco bacterial wilt. J. Plant Pathol. 102, 731-742 (2020).

21. Abo-Elyousr, K. A. M., Hashem, M. \& Ali, E. H. Integrated control of cotton root rot disease by mixing fungal biocontrol agents and resistance inducers. Crop Protect. 28, 295-301 (2009).

22. Terblanche, J. \& DeVilliers, D. A. The suppression of Ralstonia solanacearum by marigolds. In Bacterial Wilt Disease (ed. Martin, F. B.) 325-331 (Springer, 1998).

23. Liu, Y. X. et al. Tobacco bacterial wilt can be biologically controlled by the application of antagonistic strains in combination with organic fertilizer. Biol. Fert. Soils. 49, 447-464 (2013).

24. Liu, H. X. et al. Biological control of Ralstonia wilt, Phytophthora blight, Meloidogyne root-knot on bell pepper by the combination of Bacillus subtilis AR12, Bacillus subtilis SM21 and Chryseobacterium sp. R89. Eur. J. Plant Pathol. 139, 107-116 (2014).

25. Yuan, S. F. et al. Biological control of tobacco bacterial wilt using Trichoderma harzianum amended bioorganic fertilizer and the arbuscular mycorrhizal fungi Glomus mosseae. Biol. Control. 92, 164-171 (2016).

26. Zhang, C. S. et al. Tobacco bacterial wilt suppression with biochar soil addition associates to improved soil physiochemical properties and increased rhizosphere bacteria abundance. Appl. Soil Ecol. 112, 90-96 (2017).

27. Luo, L. Y. et al. The effects of Rhodopseudomonas palustris PSB06 and CGA009 with different agricultural applications on rice growth and rhizosphere bacterial community. AMB Expr. 9, 173 (2019).

28. Chen, S., Qi, G. F., Ma, G. Q. \& Zhao, X. Y. Biochar amendment controlled bacterial wilt through changing soil chemical properties and microbial community. Microbiol. Res. 231, 126373 (2020).

29. Leff, J. W. et al. Consistent responses of soil microbial communities to elevated nutrient inputs in grasslands across the globe. $P$. Natl. Acad. Sci. USA 112, 10967-10972 (2015).

30. Yang, T. et al. Resource stoichiometry shapes community invasion resistance via productivity-mediated species identity effects. Proc. R. Soc. B-Biol. Sci. 285, 20182035 (2018). 
31. Wang, R. et al. Microbial community composition is related to soil biological and chemical properties and bacterial wilt outbreak. Sci. Rep. 7, 343 (2017).

32. Coelho, M. R. R. et al. Diversity of nifH gene pools in the rhizosphere of two cultivars of sorghum (Sorghum bicolor) treated with contrasting levels of nitrogen fertilizer. FEMS Microbiol. Lett. 279, 15-22 (2008).

33. Chen, W. et al. Mechanisms by which organic fertilizer and effective microbes mitigate peanut continuous cropping yield constraints in a red soil of south China. Appl. Soil Ecol. 128, 23-34 (2018).

34. Lee, K. C. Y. et al. Genomic analysis of Chthonomonas calidirosea, the first sequenced isolate of the phylum Armatimonadetes. ISME J. 8, 1522-1533 (2014).

35. Badri, D. V., Weir, T. L., Lelie, D. \& Vivanco, J. M. Rhizosphere chemical dialogues: Plant-microbe interactions. Curr. Opin. Biotech. 20, 642-650 (2009).

36. Raza, W., Ling, N., Yang, L. D., Huang, Q. W. \& Shen, Q. R. Response of tomato wilt pathogen Ralstonia solanacearum to the volatile organic compounds produced by a biocontrol strain Bacillus amyloliquefaciens SQR-9. Sci. Rep. 6, 24856 (2016).

37. Pattee, H. E. Production of aflatoxins by Aspergillus flavus cultured on flue-cured tobacco. Appl. Microbiol. 18, 952-953 (1969).

38. Silva, R. N. et al. Trichoderma/pathogen/plant interaction in pre-harvest food security. Fungal Biol-UK 123, 565-583 (2019).

39. Scheffffer, M., Carpenter, S. R., Lenton, T. M. \& Bascompte, J. Anticipating critical transitions. Science 338, 344-348 (2012).

40. Xiong, W. et al. Distinct roles for soil fungal and bacterial communities associated with the suppression of vanilla Fusarium wilt disease. Soil Biol. Biochem. 107, 198-207 (2017).

41. Hayden, H. L., Rochfort, S. J., Ezernieks, V., Savin, K. W. \& Mele, P. M. Metabolomics approaches for the discrimination of disease suppressive soils for Rhizoctonia solani AG8 in cereal crops using ${ }^{1} \mathrm{H}$ NMR and LC-MS. Sci. Total. Environ. 651, 1627-1638 (2019).

42. Ros, M. et al. Approaches for the discrimination of suppressive soils for Pythium irregulare disease. Appl. Soil Ecol. 14, 103439 (2020).

43. Withers, E., Hill, P. W., Chadwick, D. R. \& Jones, D. L. Use of untargeted metabolomics for assessing soil quality and microbial function. Soil Biol. Biochem. 143, 107758 (2020).

44. Wu, K. et al. Root exudates from two tobacco cultivars affect colonization of Ralstonia solanacearum and the disease index. Eur. J. Plant Pathol. 141, 667-677 (2015).

45. Liu, Y. X. et al. Identification of benzoic acid and 3-phenylpropanoic acid in tobacco root exudates and their role in the growth of rhizosphere microorganisms. Appl. Soil Ecol. 93, 78-87 (2015).

46. Li, S. L. et al. Cinnamic, myristic and fumaric acids in tobacco root exudates induce the infection of plants by Ralstonia solanacearum. Plant Soil. 412, 381-395 (2017)

47. Chen, S. L., Zhou, B. L., Lin, S. S., Li, X. \& Ye, X. L. Accumulation of cinnamic acid and vanillin in eggplant root exudates and the relationship with continuous cropping obstacle. Afr. J. Biotechnol. 10, 2659-2665 (2011).

48. Badri, D. V., Chaparro, J. M., Zhang, R. F., Shen, Q. R. \& Vivanco, J. M. Application of natural blends of phytochemicals derived from the root exudates of Arabidopsis to the soil reveal that phenolic-related compounds predominantly modulate the soil microbiome. J. Biol. Chem. 288, 4502-4512 (2013).

49. Hasegawa, T. et al. Effect of secondary metabolites of tomato (Solanum lycopersicum) on chemotaxis of Ralstonia solanacearum, pathogen of bacterial wilt disease. J. Agric. Food Chem. 67, 1807-1813 (2019).

50. Song, Y., Li, X. N., Yang, X. L. \& Jiang, X. Correlations between soil metabolomics and bacterial community structures in the pepper rhizosphere under plastic greenhouse cultivation. Sci. Total. Environ. 728, 138439 (2020).

51. Yao, D. H. et al. Co-producing iturin A and poly-gamma-glutamic acid from rapeseed meal under solid state fermentation by the newly isolated Bacillus subtilis strain 3-10. World J. Microb. Biot. 28, 985-991 (2012).

52. Li, Y. et al. Soil chemical properties, 'Guanximiyou' pummelo leaf mineral nutrient status and fruit quality in the southern region of Fujian province, China. J Soil Sci. Plant Nutr. 15, 615-628 (2015).

53. Li, Y. Y. et al. Genetic diversity and pathogenicity of Ralstonia solanacearum causing tobacco bacterial wilt in China. Plant Dis. 100, 1288-1296 (2016).

54. Ros, M. et al. Approaches for the discrimination of suppressive soils for Pythium irregulare disease. Appl. Soil Ecol. 147, 103439 (2020).

55. Lykogianni, M. et al. Metabolomics reveals differential mechanisms of toxicity of hyperbranched poly(ethyleneimine)-derived nanoparticles to the soil-borne fungus Verticillium dahliae Kleb. Pestic. Biochem. Phys. 165, 104535 (2020).

\section{Acknowledgements}

This work was supported by the key technology projects of China National Tobacco Corporation (CNTC) (No. 110201502018 and No. 110201901042 (LS-05), the key technology projects of Hubei tobacco companies (No. 027Y2018-038) and the Science and Technology Research Project of Education Department of Hubei Province (D20201003). Thank to Tobacco Research Institute of Hubei for providing Yunyan87 seeds, and the local farmers in Xuan'en County of Enshi City for providing marigold roots and stems.

\section{Author contributions}

Y.Y. and Y.L. initiated and designed the research. Y.L., X.L., J.F., C.L., X.Y., Q.G. and L.W. performed the experiments and collected the data. Y.H. and W.Z. analyzed the data and wrote the manuscript. Y.Y. and S.C. revised the manuscript. All authors reviewed and approved the final manuscript.

\section{Competing interests}

The authors declare no competing interests.

\section{Additional information}

Supplementary Information The online version contains supplementary material available at https://doi.org/ 10.1038/s41598-021-95741-w.

Correspondence and requests for materials should be addressed to Y.L. or Y.Y.

Reprints and permissions information is available at www.nature.com/reprints.

Publisher's note Springer Nature remains neutral with regard to jurisdictional claims in published maps and institutional affiliations. 
(c) (i) Open Access This article is licensed under a Creative Commons Attribution 4.0 International cc) License, which permits use, sharing, adaptation, distribution and reproduction in any medium or format, as long as you give appropriate credit to the original author(s) and the source, provide a link to the Creative Commons licence, and indicate if changes were made. The images or other third party material in this article are included in the article's Creative Commons licence, unless indicated otherwise in a credit line to the material. If material is not included in the article's Creative Commons licence and your intended use is not permitted by statutory regulation or exceeds the permitted use, you will need to obtain permission directly from the copyright holder. To view a copy of this licence, visit http://creativecommons.org/licenses/by/4.0/.

(C) The Author(s) 2021 